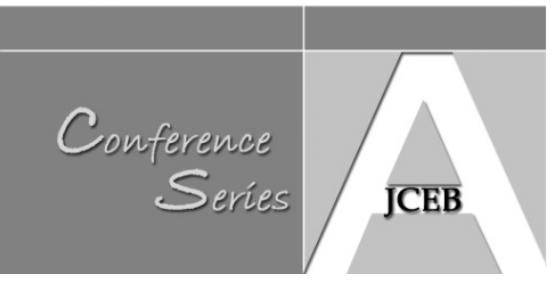

\title{
Innovative Unit Delivery - The Supported Cloud
}

Eric Chan, Linda Tivendale, Chunlu Liu and Anthony Mills (Deakin University, Australia)

\begin{abstract}
Deakin University has recently moved to an academic calendar of three trimesters. This change aims to provide students with greater flexibility to plan their study around work or life commitments, create options for students to commence their degree and enable students to fast track their study. It has been found for students in the Bachelor of Construction Management that engagement and satisfaction during summer (Trimester 3 ) are less than when those same units are delivered during other trimesters. This research addresses the use of Supported Cloud learning to improve learning and the relationship with students. The School of Architecture and Built Environment used two units as case studies to examine different innovative unit delivery strategies that combined cloud and located learning. The research design included evaluation surveys, questionnaires, and semi-structured interviews as well as reflection by participating teachers. The findings show that students' results are improved when the cloud based learning is supported by well-developed resources, structured delivery and availability of some face-to-face contacts. This innovation will serve as a benchmark for Cloud delivery in the School in all trimesters.
\end{abstract}

Keywords: Flexible Delivery, Construction Management Education, Cloud Learning, Located Learning

\section{Introduction}

Deakin University has a long history of delivering distance education. It was established in 1974 with a charter that specifically included responsibility for distance education at university level for the state of Victoria (Stacey \& Visser 2005). Deakin's commitment to flexible education remains a core component of its current strategic plan: LIVE the Future: Agenda 2020. Deakin aspires for 'a brilliant education, where students are and where they want to go' and supports each faculty to provide: 1 . premium cloud and located learning; 2. course enhancement; 3 . capacity building; 4. researching and evaluating teaching and learning.

The Strategic Teaching Enhancement Project (STEP) is part of Deakin's Course Enhancement Programme (CEP) and provided the platform for the School of Architecture and Built Environment (School $A+B$ ) to conduct action research into cloud supported learning in the Bachelor of Construction Management (BCM). STEP is a Deakin initiative to provide funding and resources with the aim to enhance and improve teaching in off campus (on-line) units, particularly those that were under-performing. The BCM offers nine core Units in Trimester 3 all of which are delivered off campus (on-line) mode with a range of delivery strategies. These Units are also offered in face to face mode during other trimesters. The School A+B applied for the STEP funding to develop innovative programs for two units that showed student satisfaction in Trimester 3 that was less than when these units were delivered in other trimesters. The two units are Project Planning and Scheduling (SRM310) and Building Cost Planning (SRQ462), which have a high component of technical content. 


\section{Literature Review}

Deakin places great emphasis on flexible learning programs, and flexible delivery by on-line platforms is important in tertiary education. Using this delivery approach, students are able to adjust the pace of learning according to their own conditions, and learning is no longer restricted to inside the lecture theatre. In studying the architecture and construction management education in Australia, Tucker \& Morris (2011) conclude that flexibility which is demanded by students is about pedagogy and delivery; whereas teachers are merely willing to offer flexibility in delivery. Thus, the focus is hinged on how knowledge is delivered to allow students' flexibility when and where they can learn.

Van den Brande (1993) postulates three flexible delivery considerations as "enabling learners to learn when they want (frequency, timing, duration), how they want (modes of learning), and what they want (learners can define what constitutes learning to them)". "How" to learn is defined by "where" the learning is taking place and "what" is to be learned. This leads to a technology-based delivery system that fit the learning purpose. However, the applicability of different technologies and the configuration of technologies in delivery of the learning material will depend on the situation of the student and the content of material. There is a need to formulate the smartest strategy in deciding an innovative flexible delivery and learning approach.

Course delivery is usually either on- or off- campus. On-campus delivery mostly relies on traditional face-to-face interaction while off-campus (on-line) delivery increasingly uses virtual class approach, i.e. e-learning. Ramsden (2003) states that two of the six principles in deciding effective strategies for tertiary education are "concern and respect for students and student learning" and "control and active engagement". Therefore, university must consider students' needs and expectations when deciding a delivery approach with the aim of enhancing student's engagement in their study.

\section{Cloud Learning Supported by Face-to-Face Components}

McShane (2004) concludes that using e-learning mode can enhance relationships with students because information communication technology (ICT) can remove age and generation barriers, and provide for a more rapid response from lecturers to students. However, planning and teaching using e-learning are very conscious tasks.

However, the use of ICT in teaching and learning, particularly on-line modes; should not initiate a role shift for the lecturer that removes contact and interaction with students. Garrison (2011) states that successful e-learning depends on the ability of the educators to create learning environments that motivate students and facilitate meaningful and worthwhile learning activities and outcomes. The teacher who designs the right balance and blend of collaborative and individual learning activities, in cloud or located environment, is one of the key ingredients.

In studying the preference of a student cohort from the school of architecture, design and the built environment, Poon (2012) finds that blended learning, i.e. including cloud and located learning components, gives greater flexibility for student learning in terms of learning style and study pace. With the adoption of a wide range of delivery methods, blended learning can successfully improve students' experience and enhance their engagement. It is always important to ensure that blended learning is really "blended" and includes a good mix of delivery methods, both virtual and real. Face-to-face interaction with students is important as students require reassurance and on-going support from teachers. Therefore, provision of face-to-face support in cloud learning is required.

Therefore, the ideal strategy for a successful innovative delivery approach, using "cloud and located learning", should include both on-line and face-to-face components.

Chan, E, Tivendale, L, Liu, C \& Mills, A. 2014, 'Innovative Unit Delivery - The Supported Cloud', Australasian Journal of Construction Economics and Building Conference Series, 2(2), 11-18. 


\section{Research Design}

As part of the CEP, this research explores whether providing on-campus support for offcampus learning, i.e. "Innovative Delivery-The Supported Cloud" can improve student engagement and outcomes. Design is based on action research principles to explore "why the students' engagement in Trimester 3 is poorer than other trimesters?", "how innovative delivery approach can improve such engagement" and subsequently "how the students' needs and expectations are addressed?" According to Yin (2003), "why" and "how" questions are more likely leading to the use of case studies. This is because such questions deal with operational links needing to be traced over time, rather than mere frequencies or incidence. Yin (2003) also state that case study research can be performed using document, video or audio tape of interview, or surveying certain group of people about their experiences.

For the "why" question, a multiple-case study approach is preferred because evidence from multiple cases is often considered more compelling. Therefore, such study should include wider array of documentary information, in addition to conducting interviews. Only with replications would the findings be robust and worthy of continued investigation or interpretation (Yin 2003).

Regarding data collection, Yin (2012) suggests that there are six common source of evidence in doing case studies: direct observations, interviews, archival records, documents, participant-observation and physical artefacts. Regardless of source, this evidence can be qualitative and quantitative. In this research, qualitative data will be collected through open ended interview with students and questionnaire and opinion surveys.

Therefore, this research is an action case study by observations, interviews and reflections. According to Tomal (2010), the study will address the problem of low student satisfaction levels with two specific units delivered in Trimester 3. The intervention included:

- Additional face-to-face support in on-line delivery

- Intensive lecture classes

- Active participation of discipline leader, course leader, and unit chair in engagement with students

\section{Data Collection}

Data was collected through a number of stages. At the commencement of Trimester 3 , students were asked to provide qualitative comments on each unit in which they were enrolled, that are, SRQ462 and SRM310. Students were later invited to participate in a semistructured interview in the middle of the trimester and a final qualitative survey at the end of the trimester. All questionnaires were distributed to students who attended on campus and were available on-line for those who were using the Cloud delivery.

The first survey asked questions relating to students' expectations for the units while the final survey asked the same questions with respect to two units' performances. In the final survey, the students were also asked if this innovative delivery method could be adopted in Trimester 1 and Trimester 2 and/or in other units. The mid-trimester interviews gauged more in depth responses to the same issues of how the blended delivery is affecting their studies and learning.

\section{Case Studies}

\section{Delivery Methods}

Academic staff proposed interventions for cloud support that were specific to each of the case study units for Trimester 3, 2012. For SRQ462, it was felt that students needed all of

Chan, E, Tivendale, L, Liu, C \& Mills, A. 2014, 'Innovative Unit Delivery - The Supported Cloud', Australasian Journal of Construction Economics and Building Conference Series, 2(2), 11-18. 
the discipline content in order to understand the practical outcomes required for both assessment and real world practice. SRQ462 was therefore delivered using one day of intensive lectures each week for the first three weeks of the trimester. The lectures were presented in a seminar style with a professional environment adopted. It included introductions to on-line technology options including "eLive" and "ePortfolio" to ensure that students felt comfortable using these technological supports when studying in the off campus environment. On campus delivery was completed prior to the Christmas break which has been identified as a key disengagement point with students. This was followed by six weeks of on-line discussion, quizzes and self-assessment activities to strengthen the students' background knowledge, to allow for practice of outcomes and reinforce learning. A further face to face revision lecture was held in the last week of Trimester 3 prior to the final examination.

SRM310 is a highly technical unit that can be difficult for students to understand without step-by-step instructions, repetition and graphics. As well, students need to practice one application before proceeding to the next. SRM310 was therefore structured to provide faceto-face workshops and brief lectures at key points in the delivery road map, facilitated by industry practitioners in construction scheduling. Again, a professional terminology (workshop, seminar) and format was adopted. On-line lecture resources, discussions and tutorials with the Unit Chair were included throughout the trimester.

In both units, the on campus lectures were recorded and made available to all students through "CloudDeakin", the university's web-based student portal. All learning resources were also available on "CloudDeakin". Attendance at the Cloud supported activities was consistent throughout the trimester, with more than 20\% attending for SRQ462 while over $30 \%$ attend for SRM310.

\section{Responses}

In Trimester 3, 2012, there were 47 students enrolled in SRQ462 and 25 students in SRM310. Responses were received from 34 students for the first survey and 17 students for the final survey. Mid-trimester interviews were held with four students.

At the commencement of the trimester, the great majority of students had high expectations that both the on-line and the face-to-face components of the units would enhance their learning experience.

"A great positive move in the first stage of regenerating SRM310."

"I am so impressed to see how quick Deakin University reflects on student's feedback from this matter."

"It is great to have both on-line and face to face teaching. The combination allows for a greater increase in knowledge import."

Student feedback as the trimester proceeded remained positive. Student comments related to: 1. personal contact and communications with teaching staff; 2. work-life-study balance; 3. learning modes and resources.

\section{Personal Contact and Communications}

Students noted that it is normally difficult in the summer trimester to find 'mutually agreeable' times for meetings with staff. They felt this barrier was minimal during the STEP program, even if they were not attending the lectures or workshops, as there was more structure to delivery overall.

Many students highlighted the quick response by staff to emails or Discussion Board posts posted on "CloudDeakin". Staff noted that, in part, this was due to their enthusiasm for the

Chan, E, Tivendale, L, Liu, C \& Mills, A. 2014, 'Innovative Unit Delivery - The Supported Cloud', Australasian Journal of Construction Economics and Building Conference Series, 2(2), 11-18. 
intervention and their willingness to make it a success. Students also appreciated contact with their peers and the learning that arose from that.

"You're working with your peers, so you learn faster with groups of people, and yeah, they're the main reasons l've found it beneficial."

Peer support is an aspect of learning that is often absent from on-line units. Student use of the Discussion Board seemed to be evenly spread between those who attended at least some face-to-face and those who did not. It was not possible to determine peer support offered to those not in attendance.

Another key positive outcome for students was the ability of staff to react quickly to learning and delivery issues. SRM310 revised the timing and length of tutorial workshops based on students' feedback and requests. The workshops were also aligned more closely to assignment submission dates. Academics found communications with students improved. The opportunity to engage less formally with students during lunch enhanced relationships. While this is not feasible for traditional unit delivery, it was a simple measure that added a level of mutual respect and understanding for all participants in the learning experience.

The active communication role taken by non-teaching staff, including discipline leader and course leader, also promoted an open and inclusive environment, particularly for students who did not attend on-campus.

\section{Work-Life-Study Balance}

Students made it clear in the initial survey that balancing study with their life is more difficult over the summer trimester.

"The hardest part about summer school is managing work load."

"(My likely attendance is) unknown due to commitments changing throughout the holidays."

As the trimester proceeded, studentsfelt that their workload was not as strenuous as expected "... despite still having four units." They were able to relate this improvement directly to the revised delivery strategies, particularly for SRQ462 where intensive lectures were introduced.

"It is far easier to take a whole day off work than be back and forth from work to university."

"From a time management perspective, having the intensive days is fantastic."

A recurring topic with respect to their more balanced trimester was the perception by students that their learning was 'faster' with face-to-face support. Students also felt they gained a more clear understanding of assessment requirements.

“... it's fast tracked the learning process just by having a quick workshop with him there."

The funding provided by the STEP program allowed academic staff the necessary support to prepare for the face-to-face classes. There was, however, a perception that these oncampus classes provided structure and consistency to the summer and that staff, like the students, were kept on track and connected during the trimester.

Chan, E, Tivendale, L, Liu, C \& Mills, A. 2014, 'Innovative Unit Delivery - The Supported Cloud', Australasian Journal of Construction Economics and Building Conference Series, 2(2), 11-18. 


\section{Learning Modes and Resources}

Learning resources available to students on "CloudDeakin" included copies of lecture presentations, recordings of lecture presentations, copies of workshop materials, Discussion Board posts, and, for SRQ462 only, tutorial questions and "eLive" access for tutorials. Students agreed that there was a large amount of material available on-line. They felt that the addition of face-to-face support made it easier to navigate the on-line materials, provide a "broader, wider and clearer" context and gave more structure to their learning. They also believed that by covering a lot of material in a shorter space of time it allowed them more time for reflection of their learning. Students commented on their better use of the reading materials as they had a much better idea of the overall content and framework for the subject material.

The word 'flexibility' was used frequently in reference to the ability to attend on-campus; the cloud based delivery options and the range and availability of learning materials. They talked about 'windows of help' in reference to email, "CloudDeakin" and face-to-face contact, as well as options for review if they did not understand the work. They noted the obvious advantage of on-line delivery in that 'you don't need to travel to uni' which can be a substantial attraction given Deakin's regional location. The availability of lecture recordings on-line was critical for those who attended as well as those who did not.

\section{Student Outcomes}

It is difficult to measure the success of the intervention with respect to student outcomes or retention. Nevertheless, the improvement of students' results after the implementation of the "Innovative Delivery - The Supported Cloud" approach are observed. SRQ462 was first taught in the summer trimester in 2009 while SRM310 has been taught in Trimester 3 since 2006. Both units are also taught in Trimester 2. In consideration with the availability of data, outcomes of these two units in Trimester 32012 are compared to those only from 2008 to 2011. Figure 1 presents the distributions of students with five categories of marks in Trimester 32012 in comparison with average percentages in Trimester 3 from 2008 to 2012 for each unit. The percentages of students in Trimester 32012 drastically decreased in the two low categories compared to those from 2008 to 2011. In Trimester 3 2012, 8 out of 45 students in SRQ462 and 9 out of 25 students in SRM310 reached 80 or higher marks. These ratios were never achieved in previous years. Comparisons of distributions indicate that the STEP applied in Trimester 32012 improved students' learning outcomes.
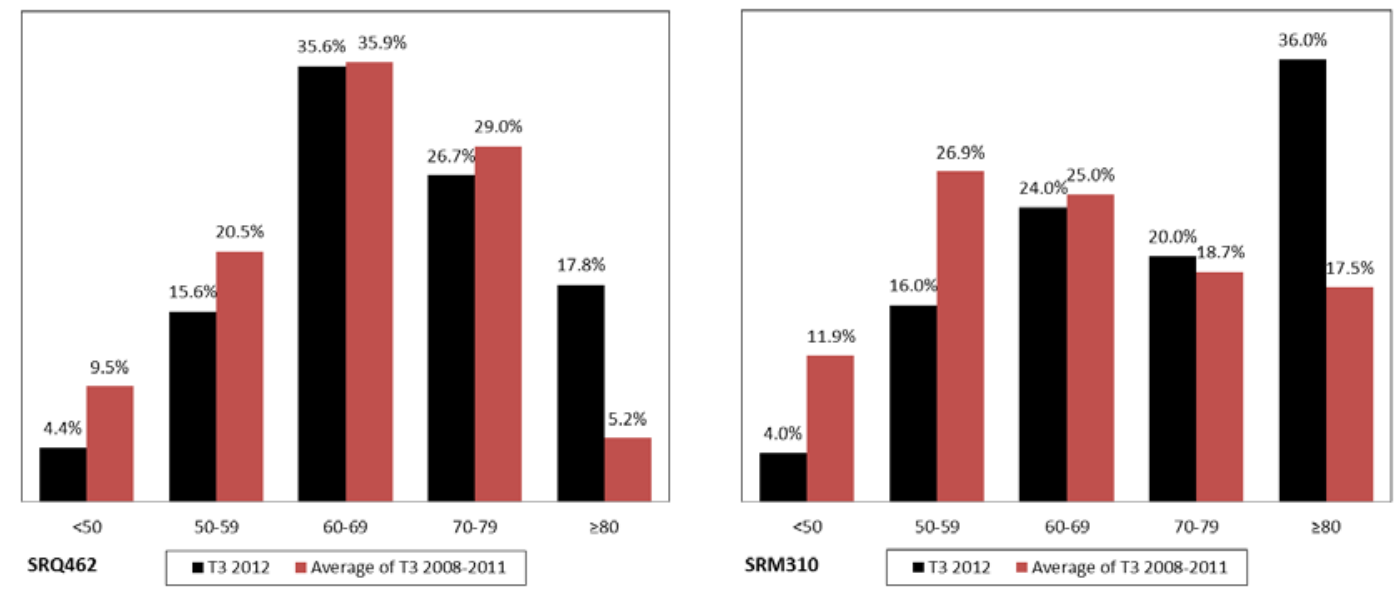

Figure 1. Comparison of Result Distributions in SRQ462 \& SRM310

Chan, E, Tivendale, L, Liu, C \& Mills, A. 2014, 'Innovative Unit Delivery - The Supported Cloud', Australasian Journal of Construction Economics and Building Conference Series, 2(2), 11-18. 


\section{Barriers and Success Factors}

Probably the most critical factor in on-line learning is the successful performance of the online learning platform. The interventions for these units were structured so that students were not required to attend for what were, in reality, on-line units. Nevertheless, there was concern from students that they may be disadvantaged by not attending. This concern was reiterated throughout the trimester.

"I worry for the people that haven't come to the tutorials."

“... as an on-line student, I felt I definitely got the rough end of the stick compared to those who actually attended."

Given this apprehension, it was unfortunate that on-going difficulties with the sound quality and availability of lecture recordings occurred during Trimester 3, 2012. The majority of negative comments from students related to the poor quality or non-existent lecture recordings. Students' anxiety was minimised due to the improved communications by staff together with the University's obvious attempts to rectify the problems.

Students were also concerned about the addition of face-to-face activities for units publicised as 'on-line'. Future use of face-to-face activities for on-line units will be clearly outlined in the University Handbook to ensure students' make informed choices when selecting their trimester of study.

One of the noteworthy aspects of this research was that students were appreciative of the attempt to make changes in these specific units, regardless of any perceived benefits.

"I appreciate the time that has been put in to allow us to do it this way."

"Thanks for trying to improve things and listening."

It was also clear that, the majority of students in this research, including those who did not attend any on-campus activities, stated that they prefer face-to-face learning.

"If I had my choice, I would want it solely on campus."

"Personally, I prefer face-to-face."

The preference for face-to-face learning, however, does not equate to the actual attendance on campus. Students will determine attendance based on factors other than their educational needs. Competing factors included distance, holidays, work, study in other units, and family. These factors are magnified in Trimester 3, particularly with respect to families and holidays.

\section{Conclusions}

Continuous and reflective evaluation of teaching and learning allows for targeted changes in delivery and assessment. The STEP interventions were used to target units that, for a number of years, had low student evaluations over Trimester 3. Despite students' preference for face-to-face learning, there is increasing demand for on-line units and increasing numbers of students in on-line classes. Students identified that face-to-face classes provided the peer support, staff contact and engagement that will lead to improved learning, but that this is countered by the pressures of employment and family, and the flexibility required to learn "where students are". Nevertheless, students believe that cloud supported learning can

Chan, E, Tivendale, L, Liu, C \& Mills, A. 2014, 'Innovative Unit Delivery - The Supported Cloud', Australasian Journal of Construction Economics and Building Conference Series, 2(2), 11-18. 
work and is well suited for these two units. They believe it could be suitable for other units, though not for first year studies.

Academics were overwhelmingly pleased with the changes to these units. The ability to continue to provide changes, without the support provided by STEP funding, still needs to be addressed. The challenge for academics is how to provide the benefits of face-to-face learning in an on-line environment. Offering supported Cloud delivery is one means of achieving this. Face-to-face workshops need to be added in a structured manner so that no students are disadvantaged. They also need to add value to Cloud based material, rather than replicate a traditional tutorial or lecture. Academics need to be innovative and interrogate their units to identify 'Cloud' and 'located' suitability. Further research will continue to explore how this blend can best be achieved.

\section{References}

Garrison, D.R. 2011, E-Learning in the 21st Century : A Framework for Research and Practice, Taylor and Francis, Hoboken.

McShane, K. 2004, 'Integrating face-to-face and online teaching: academics' role concept and teaching choices', Teaching in Higher Education, 9(1), 3-16.

Poon, J. 2012, 'Use of blended learning to enhance the student learning experience and engagement in property education', Property Management, 30(2), 129-56.

Ramsden, P. 2003, Learning to Teach in Higher Education, 2nd edn, Routledge Falmer, London.

Stacey, E \& Visser, L. 2005, 'The History of Distance Education in Australia', Quarterly Review of Distance Education, 6(3),253-9.

Tomal, D.R. 2010, Action Research for Educators, Rowman \& Littlefield.

Tucker, R \& Morris, G. 2011, 'Anytime, anywhere, anyplace: Articulating the meaning of flexible delivery in built environment education', British Journal of Educational Technology, 42(6), 904-15.

Van den Brande, L. 1993, Flexible and Distance Learning, John Wiley \& Sons, Inc.

Yin, R.K. 2003, Case Study Research: Design and Methods, 3rd edn, SAGE Publications, Incorporated.

Yin, R.K. 2012, Applications of case study research, 3rd edn, SAGE Publications, Incorporated.

Chan, E, Tivendale, L, Liu, C \& Mills, A. 2014, 'Innovative Unit Delivery - The Supported Cloud', Australasian Journal of Construction Economics and Building Conference Series, 2(2), 11-18. 